\title{
FROM VISION TO REALITY
}

Iceland is successfully building an integrated infrastructure for egovernment and e-commerce

Jóhann Gunnarsson ${ }^{1}$ and Gudbjorg Sigurdardóttir ${ }^{2}$

${ }^{I}$ Ministry of Finance of Iceland, Arnarhvoli, IS-150 Reykjavik, Iceland. ${ }^{2}$ The Information Society Task Force, Prime Minister's Office, IS-150 Reykjavik, Iceland

Abstract: Based on a 1996 vision of the information society, the government of Iceland is building the components of an integrated infrastructure to enable egovernment and e-commerce. A sound economy, advanced communications facilities, high penetration of computers in businesses, homes and schools as well as openness towards innovation in the general public form an ideal basis for rapid adaptation of government services towards self service, citizen participation and information sharing. This paper tells some success stories and seeks to analyse the key enabling factors.

Key words: Stream 5, Information society, e-government, e-business, Iceland.

\section{INTRODUCTION}

Iceland is a large island in the North Atlantic ocean. It is one of the most scarcely populated countries in Europe. The population of Iceland is about 286,000 and roughly 62 percent thereof live in the capital city, Reykjavik, and neighbouring municipalities. ${ }^{2}$

Living standards in Iceland are among the highest in the world. The economy, based on fisheries and agriculture at the beginning of this century, has diversified into manufacturing and service industries and is now transforming into a diverse modern digital economy where about $77 \%$ of the population have access to the Internet according to an Internet survey

${ }^{2}$ Source: http://www.statice.is/

The original version of this chapter was revised: The copyright line was incorrect. This has been corrected. The Erratum to this chapter is available at DOI: 10.1007/978-0-387-35604-4_20 
conducted in March 2001. ${ }^{3}$ Sophisticated telecommunications facilities, through fibre-optic cable connections, offer reliable direct international links for telephone, fax and data networks.

Telecommunications are deregulated and telephone charges in Iceland are the lowest within the OECD. The establishment of a single rate for phone calls anywhere within Iceland in 1999, thereby eliminating regional costdisparities, represented a milestone in telecommunincations.

Iceland was the first country in the world to set up a fully digital phone network. The European integrated services digital network (ISDN) has been in operation in Iceland since 1995. ADSL is growing in popularity as a last mile solution, but a variety of possibilities exist in urban areas, including fibre to the home and power-line communications. International connections are by fibre-optic sea cable and satellite. All urban communities around the country are linked by fibre-optic cable. Data transfer capacity of $128 \mathrm{~Kb} / \mathrm{s}$ is defined as a universal service requirement by telephony service providers ${ }^{4}$.

Extensive cellular mobile phone systems are also operated. According to the above-mentioned survey, $80.1 \%$ of Icelanders between the ages of 16 and 75 use GSM mobile phones, and $52.3 \%$ use SMS text messages. Findings from the March 2001 survey show that $76.9 \%$ of Icelanders $(74.7 \%$ of women and $79 \%$ of men) have access to a computer with an Internet connection. It also reveals that $67.8 \%$ of Icelanders have access to the Internet at home. Furthermore, $87.2 \%$ of those who have access to the Internet have an e-mail address and well over half of those who have access to the Internet (57.5\%) use it daily or almost daily. The survey indicates that $22 \%$ of Icelanders with Internet access have purchased goods or services over the Internet.

\subsection{The Information Society Task Force}

In October 1996 the Government of Iceland published a paper titled "The Government of Iceland's Vision for the Information Society".

The paper presents the government's strategy for information society issues. In this strategy it is proposed, among other things, to capitalize on two kinds of qualities that are deeply rooted in the Icelandic national character. On one hand, the nation is strongly motivated towards progress

${ }^{3}$ The Information Society Task Force has regularly commissioned surveys of computer ownership and Internet use in Iceland over the period 1998-2001. The most recent one at the time of writing can be found at http://www.iceland.is/it/internet/index.html

${ }^{4}$ The Telecommunications Act of 1999 in English: http://www.pta.is/English/estart.htm

${ }^{5} \mathrm{http}: / / \mathrm{www}$ 2.stjr.is/framt/vision00.htm 
and open to innovation. On the other hand, Icelanders have a sincere conviction of their cultural uniqueness.

Pertaining to the latter item, it so happens that Iceland's cultural heritage consists, for the most part, of information, i.e. it is a written and historically based heritage. Information and telecommunications technology, therefore, not only open up new possibilities for the future development of Icelandic society, but also create a turning point in the presentation and understanding of the cultural values the nation has created in past centuries.

Following the publication of the strategy, the government decided to establish a development project for the information society in Iceland. The project was originally planned to end September 1, 2002, but has been extended for one year. A steering group, The Information Society Task Force, operating under the auspices of the Office of the Prime Minister, steers the Information Society Project.

The main role of the Information Society Task Force is to promote the implementation of the government's strategy.

\section{WHAT HAS BEEN ACHIEVED?}

The following overview of achievements or milestones on the way to the information society, mainly deals with the public sector. Since its establishment, the Information Society Task Force has initiated and supported a number of activities, but the contribution of various Government institutions and the legislators to the information society has also been extensive and has a long history.

It has already been mentioned that Icelanders are few in numbers, or just under 300 thousand people, living in a relatively large country. As an independent nation with complete administrative, educational and health systems, as well as foreign trade and diplomacy, Iceland needs to maintain a relatively heavy overhead. As an example, Icelanders are roughly 15 times fewer in numbers than the two small neighbouring countries, Ireland and Norway.

\subsection{Successful E-government Applications}

One of the key factors contributing to efficiency both in government and businesses is the existence of a reliable central national register of persons and firms. The register features a unique identification number for each individual (CPR-number). The CPR-numbers are used for the purpose of

${ }^{6}$ As an example, see http://www.saganet.is 
identifying individuals in the government's systems as well as in banks and other businesses. Therefore, these numbers are an extremely important tool for reliable identification in Icelandic IT systems. Although the widespread use of the CPR-numbers has been criticized, mainly for reasons of personal privacy, the consensus seems to be that the advantages outweigh the risks.

It would seem natural for a small organization like the Icelandic public sector to seek to harmonize as far as possible any computer systems, as it is likely to pay off both in cost and efficiency. This, however, does not just happen automatically. In some areas the Icelandic administration has been quite successful in implementing common solutions that do improve efficiency, and at the same time make it easier for the general public to communicate with the administration. Some examples are given below.

\subsubsection{A common groupware and document handling solution for government offices and embassies}

Starting in 1995, in cooperation with a local software company, three government offices jointly developed a document handling system based on a widely marketed groupware package. Soon all other ministries joined in and joint design goals were defined. The system has now become indispensable in all ministries and embassies, both as a management tool and in fulfilling the government's obligations respective to the Information Act of 1996. Parallel to this, the system is being successfully marketed worldwide by the developer.

\subsubsection{Integrated financial and human resources systems for the Icelandic government}

The Icelandic administration is undertaking a renewal of its major software systems. This may well be the most extensive and integrated implementation by an entire government ever undertaken. It involves 19,000 employees in around 300 institutions. Based on a well known, Web enabled e-business software suite, it is intended to provide the foundation for implementing e-government as well as employee and citizen relationship management in Iceland. The new systems are replacing legacy systems, some dating as far back as 1978 , and will bring with them a wide-ranging structural change in the administration.

\subsubsection{Electronic marketplace}

An agreement has been signed with a service provider to set up and operate an electronic marketplace for public procurement. Through the 
electronic marketplace, government institutions will have access to their suppliers' catalogs and price lists in a standardized format. They will be able to compare current prices and place orders. The suppliers will be able to confirm orders, issue electronic invoices, and the Marketplace software will be linkable to both parties' accounting systems. The first transactions are planned to take place late 2002 .

\subsubsection{PKI}

In order to strengthen the security of the planned and existing egovernment activities, a public key infrastructure is being developed. Based on international and European standards, the aim is to develop a government PKI around a set of certificates according to the defined requirements of the administration.

\subsubsection{Access to public sector information}

Various measures have been taken to increase the availability of public sector information on the Web. All laws, regulations, most court decisions and a vast amount of information concerning the government and its institutions is now available through the government portal, www.raduneyti.is.

\subsubsection{Libraries and databases}

A consortium has been established, where all libraries in the country unite in operating a common library system, thus creating an integrated virtual library for the whole nation. Under the leadership of the ministry of education, science and culture, contracts have been signed with major international suppliers of reference material to make available to anyone under the .is top level domain some 31 databases, over 6,000 magazines and more. $^{7}$

\subsection{Top Performers}

In a number of areas, interactive applications set up by government agencies have reached exceptionally high levels of penetration in the respective user groups. The following three examples were awarded an egovernment label at a conference on e-government held by the European Union and the Government of Belgium in November 2001.

${ }^{7} \mathrm{http}: / / \mathrm{www} \cdot \mathrm{hvar}$.is 


\subsubsection{Information system on landed catch and fishing quotas of individual fishing vessels}

The system receives information on landed catches by all fishing vessels, from all ports of landing in Iceland on a daily basis through a computer network. Data on quotas and transfer of quotas is also submitted to the system. The system is operated under the auspices of the Directorate of Fisheries $^{8}$. The purpose is to help manage the following tasks, which are among the directorate's duties: allocation of catch quotas; supervision of transfers of quotas; collection of catch data and monitoring the quota status of individual vessels. The current status in each category is accessible at any time on the Web.

Considering the importance of fisheries and fish processing in the country's economy this system plays a key role.

\subsubsection{Electronic tax returns}

Electronic tax returns have been possible for businesses since 1997 and since 1999 for individuals. In 2001, 85\% of businesses and $63 \%$ of individuals used this method for their returns. For the citizen, the benefits are a user-friendly system with on-line guidance, certain data pre-entered, automatic calculation of totals and rule-based consistency checking. During the declaration period the system, including help desk, is available around the clock. It is possible to work in sessions and save intermediate results until ready for submission.

For the tax authorities ${ }^{9}$ the benefits are faster and easier filing, higher quality of data, reduced cost and the possibility of using artificial intelligence auditing, which makes it possible to approve $40 \%$ of electronic returns without any manual intervention.

\subsubsection{Electronic customs clearance of goods over the Internet using digital signature}

With the Customs Law adopted 1987 it was made possible to submit customs declarations and receive clearance notices electronically using EDI and X.400 protocols. A 1996 amendment to this law made it compulsory for all importers of goods to take up electronic submissions by 2001. Although up to $70 \%$ of customs declarations were submitted electronically in 1999 , it was felt that to reach the remaining, mostly small businesses, it would be

\footnotetext{
${ }^{8} \mathrm{http}: / / \mathrm{www}$. fiskistofa.is/dirfish/

${ }^{9}$ Internal Revenue Directorate. http://www.rsk.is
} 
necessary to offer a Web-based solution using digital certificates for authentication.

The only investment for the user is to have access to the Internet, a web browser, and a digital signature certificate, which is provided by the customs authorities. The service is open around the clock. For the users this solution rationalizes their work in preparing and submitting customs declarations, it saves time and is reliable, as declarations are automatically checked for errors.

From the point of view of the customs authorities ${ }^{10}$, firstly, the target of having all import and export firms submitting electronically by year-end 2001 has been reached. Secondly, the customs internal processes have been fully automated, making them able to better meet the demand for rapid flow of goods in international trade.

\section{WHY ICELAND CAN BE IN THE FOREFRONT - SIX POSSIBLE SUCCESS FACTORS}

It has been shown above that the development of the information society has been rapid and successful in Iceland. It is only natural to ask why.

The progress of a revolutionary development like the absorption of information technology in a society certainly is influenced by many factors. Below, some of those that might be special to Iceland are suggested.

\subsection{The Economy}

One reason may be high standard of living, together with a period of a healthy and growing national economy. Both businesses and individuals have had the means to buy computer equipment and software applications. Together with an innate tendency for optimism, it is generally believed that investment in technology will pay off in better business results. Icelandic businesses are very small but highly adaptive to innovation, one of the reasons being that in a small company each person must be ready to handle a wide variety of tasks.

\subsection{The Education System}

In Iceland many schools took up computer education at an early stage, and were among the first worldwide to bring Internet connectivity to the 
classrooms, even in primary schools. Information technology has now been incorporated in the curriculum at all levels. For some time, heavy emphasis has been on the reeducation of teachers and a few model schools have been assigned with the task of staying abreast of the development. These facts, in conjecture with the overall high penetration of computers, mean that information technology is considered a natural part of daily life for most of the younger generation.

\subsection{Geographical Situation}

Many people believe that the geographical situation of the country, far away in the North Atlantic ocean, undeniably isolated, has influenced the development of the Icelandic society to a considerable extent. Despite high travel costs Icelanders have, during the centuries, sought higher education to other countries. In recent years they are seeking equally to Europe and North-America, bringing back the best of both worlds in science, culture and technology. The Internet has opened in a new dimension of communication across the ocean, both for maintaining old liaisons and making new ones. Because of the geographical isolation Icelanders might be even more eager than citizens of many other countries to use this new medium.

\subsection{Democratic Tradition}

There is a strong democratic tradition in Iceland. Being an independent nation (since 1918) is highly treasured by most people. In the past, exchange of opinions about current political issues has been lively at meetings and in the press, but has now found a new, convenient medium in the Internet. Prominent politicians maintain their own web sites where they regularly discuss current issues. It is also encouraging to find how young people flock to the Internet and the Web to exchange opinions about political issues and other subjects of interest. Politicians and authorities have opened up communication paths via e-mail and the Web, as a means of shortening the distance between the general public and the authorities.

\subsection{Opportunity for the Rural Areas}

The opportunity to communicate with others, to search for information and to enjoy distance education via the Internet was discovered and appreciated at an early stage by the inhabitants of rural Iceland. An accumulated need for education was soon met by several schools at all levels, resulting in a comprehensive selection of courses that can be taken 
independent of location. In this way a considerable number of people have become acquainted with the information society at an early stage. Despite the fact that not everybody has the ideal bandwidth, this new medium has helped surmount large physical distances and dark, snowy winters.

\subsection{Receptiveness to Technology}

It is safe to say that there is a huge interest in general for new technology. People readily buy all kinds of new gadgets, such as cell phones and computers. Children get them as Christmas gifts or birthday presents. The national debate about computers and information technology has been open and on positive terms. In general, IT is considered to be an important tool in business and education. The downside, such as hacking or the collection and improper use of personal data, has not been subject to much discussion on the local websites or in the press. It has been mentioned earlier that the widespread use of the national register of persons is not being seriously challenged, even though it reveals a person's birth date and year.

\section{CONCLUSIONS}

The chief objective of the 1996 future vision of the information society that "Iceland should be in the forefront of the world's nations in the utilisation of information technology in the service of improved human existence and increased prosperity" may seem bold. It has been shown above that at least in some areas the objective has been met. Certain qualities said to be a characteristic of the Icelandic people, such as a high level of culture, the dissemination of computers and computer literacy, developed systems of management and telecommunications networks as well as the smallness of the society that makes it possible to take and implement decisions in a relatively short time, have undoubtedly helped to give it some substance. But a sound, comprehensive implementation plan, strong project management by the information society task force, and backing both by politicians and senior officials have provided the real driving force.

The lesson? Given the right conditions it is possible through sound projects and intuitive leadership to get public institutions, businesses and the general public to work together at building an effective information society. 